\title{
Social rationalizability with mediation
}

Citation for published version (APA):

Herings, P. J-J., Mauleon, A., \& Vannetelbosch, V. (2021). Social rationalizability with mediation.

Maastricht University, Graduate School of Business and Economics. GSBE Research Memoranda No. 019 https://doi.org/10.26481/umagsb.2021019

Document status and date:

Published: 02/12/2021

DOI:

10.26481/umagsb.2021019

Document Version:

Publisher's PDF, also known as Version of record

\section{Please check the document version of this publication:}

- A submitted manuscript is the version of the article upon submission and before peer-review. There can be important differences between the submitted version and the official published version of record.

People interested in the research are advised to contact the author for the final version of the publication, or visit the DOI to the publisher's website.

- The final author version and the galley proof are versions of the publication after peer review.

- The final published version features the final layout of the paper including the volume, issue and page numbers.

Link to publication

\footnotetext{
General rights rights.

- You may freely distribute the URL identifying the publication in the public portal. please follow below link for the End User Agreement:

www.umlib.nl/taverne-license

Take down policy

If you believe that this document breaches copyright please contact us at:

repository@maastrichtuniversity.nl

providing details and we will investigate your claim.
}

Copyright and moral rights for the publications made accessible in the public portal are retained by the authors and/or other copyright owners and it is a condition of accessing publications that users recognise and abide by the legal requirements associated with these

- Users may download and print one copy of any publication from the public portal for the purpose of private study or research.

- You may not further distribute the material or use it for any profit-making activity or commercial gain

If the publication is distributed under the terms of Article $25 \mathrm{fa}$ of the Dutch Copyright Act, indicated by the "Taverne" license above, 


\section{Maastricht University}

P. Jean-Jacques Herings,

Ana Mauleon, Vincent Vannetelbosch

Social Rationalizability with Mediation

$\mathrm{RM} / 21 / 019$

ISSN: $2666-8807$

\section{GSBE}

Maastricht University School of Business and Economics

Graduate School of Business and Economics

P.O Box 616

NL- 6200 MD Maastricht

The Netherlands 


\title{
Social Rationalizability with Mediation
}

\author{
P. Jean-Jacques Herings* Ana Mauleon ${ }^{\dagger} \quad$ Vincent Vannetelbosch ${ }^{\ddagger}$
}

November 26, 2021

\begin{abstract}
We propose a solution concept for social environments called social rationalizability with mediation that identifies the consequences of common knowledge of rationality and farsightedness. In a social environment several coalitions may and could be willing to move at the same time. Individuals not only hold conjectures about the behaviors of other individuals but also about how a mediator is going to solve conflicts of interest. The set of socially rationalizable outcomes with mediation is shown to be non-empty for all social environments and it can be computed by an iterative reduction procedure. We show that social rationalizability with mediation does not necessarily satisfy coalitional rationality when the number of coalition members is greater than two.
\end{abstract}

Key words: social environments; rationalizability; mediation; coalitional rationality.

JEL Classification: C70, C72, C78.

${ }^{*}$ Maastricht University, Maastricht, The Netherlands. E-mail: p.herings@maastrichtuniversity.nl

${ }^{\dagger}$ CEREC, UCLouvain Saint-Louis - Brussels; CORE/LIDAM, UCLouvain, Louvain-la-Neuve, Belgium. E-mail: ana.mauleon@usaintlouis.be

$\ddagger_{\mathrm{CORE}}$ LIDAM, UCLouvain, Louvain-la-Neuve, Belgium. $\quad$ E-mail: vincent.vannetelbosch@uclouvain.be 


\section{Introduction}

Social environments (Chwe, 1994) constitute a framework in which it is possible to study how groups of agents interact in a society. It specifies what each coalition can do if and when it forms. Social environments are general enough to encompass the representation of a cooperative game, an extensive-form game with perfect information, as well as a normal-form game. ${ }^{1}$

We propose a new solution concept for social environments called social rationalizability with mediation that identifies the consequences of common knowledge of rationality and farsightedness. Given that social environments mainly deal with the behavior of coalitions, whereas rationalizability is about the implications of rationality of individuals, we convert coalitional behavior into individual behavior. Individual participation in a coalition basically reverts either to agree to a coalitional move or to object to it and block it. In a social environment several coalitions may and could be willing to move at the same time. Conflicts of interest may arise: one coalition may try to preempt the move of another coalition or coordination problems in and between coalitions may arise. We assume that individuals not only hold conjectures about the behaviors of other individuals but also about how a mediator is going to solve conflicts of interest.

In the rationalizability approach, conjectures are not assumed to be correct, but are only constrained by considerations of rationality: individuals are rational and this is common knowledge. That is, each individual believes that the behavior of every other individual is a best response to some conjecture on every other individual's behavior, and further, each individual assumes that every other individual reasons in this way and hence believes that every other individual believes that every other individual's behavior is a best responses to some conjecture, and so on.

Central to social rationalizability with mediation are the notions of individual behavior and of conjectures about the mediator's behavior. An individual behavior describes, for each history, the coalitional moves the individual agrees to join and those she decides to block. The mediator (player 0 whose payoff is always zero) chooses a move for each possible set of moves on which the individuals could agree to join, and individuals hold conjectures about the behavior of the mediator. Our definition of social rationalizability is motivated by Pearce's (1984) original extensive-form rationalizability. ${ }^{2}$

We show that the set of socially rationalizable outcomes with mediation is non-empty for all social environments and it can be computed by an iterative reduction procedure. Since social environments deal with coalitional moves, one may wonder if social rationalizability with mediation satisfies, in general, the property of coalitional rationality. That is,

\footnotetext{
${ }^{1}$ Chwe (1994) and Xue (1998) propose, respectively, the largest consistent set and the optimistic or conservative stable standards of behavior as solution concepts for social environments. The largest consistent set may fail to satisfy individual rationality while the stable standards of behavior may be empty-valued or rule out too much.

${ }^{2}$ Related papers to extensive-form rationalizability are among others Bernheim (1984), Shimoji and Watson (1998), Vannetelbosch (1999).
} 
in a situation in which a coalition of two or more individuals can move from a status quo to different outcomes that are Pareto ranked, does social rationalizability with mediation prescribe that players coordinate on the outcome that Pareto dominates all others? We find that social rationalizability with mediation does not necessarily satisfy coalitional rationality when the number of coalition members is greater than two.

The most closely related paper to ours is Herings, Mauleon and Vannetelbosch (2004) who also define rationalizability for social environments. There are two main differences. First, they do not define rationalizability directly on the social environment but rather embed the social environment in a multi-stage game and then use the notion of extensiveform game rationalizability by Pearce (1984) to solve the multi-stage game. Second, their mediator is a dummy player whose payoff is always zero but who chooses an action consisting of a permutation of the set of feasible moves after each history. Such a permutation indicates the order according to which moves are implemented. Suppose that, from a status quo, individuals can move to three outcomes $x_{1}, x_{2}$, and $x_{3}$. The mediator imposes a ranking over those three outcomes, for instance, $\left(x_{2}, x_{3}, x_{1}\right)$. If the individuals find the moves to $x_{1}, x_{2}$, and $x_{3}$ acceptable, then $x_{2}$ is implemented. If they only agree on $x_{1}$ and $x_{2}$, then $x_{2}$ is still implemented. Such behavior of the dummy player guarantees that individuals coordinate on the Pareto-dominant outcome. However, with a more general mediator, it may happen that if the individuals find the moves to $x_{1}, x_{2}$, and $x_{3}$ acceptable, then the mediator chooses to implement $x_{2}$. But, if they only agree on $x_{1}$ and $x_{2}$, then she chooses to implement $x_{1}$ instead. We show that once the behavior of the mediator is not constrained to the choice of a permutation over alternatives, individuals may fail to coordinate on the Pareto-dominant outcome.

Besides the largest consistent set and the optimistic or conservative stable standards of behavior, another common notion for analyzing outcomes that emerge in the long run when individuals are farsighted is the farsighted stable set (Chwe, 1994; Herings, Mauleon and Vannetelbosch, 2009; Mauleon, Vannetelbosch and Vergote, 2011; Ray and Vohra, 2015). ${ }^{3}$ However, the farsighted stable set suffers from a conceptual drawback: the maximality issue. For instance, while coalitional moves improve on existing outcomes along a farsighted objection, coalitions might do even better by an alternative deviation. Dutta and Vohra (2017) propose the rational expectations farsighted stable set and the strong rational expectations farsighted stable set that restrict coalitions to hold common, history-independent expectations that incorporate maximality regarding the continuation path. More recently, Ray and Vohra (2019) incorporate absolute maximality into the definition of the farsighted stable set. Absolute maximality requires immunity to all deviations, not just by the coalition that moves or by those coalitions that intersect the

\footnotetext{
${ }^{3}$ Alternative notions of farsightedness are suggested by Bloch and van den Nouweland (2020), Diamantoudi and Xue (2003), Dutta, Ghosal and Ray (2005), Dutta and Vohra (2017), Dutta and Vartianen (2020), Herings, Mauleon and Vannetelbosch (2009, 2010, 2019, 2020), Karos and Robles (2021), Kimya (2020), Luo, Mauleon and Vannetelbosch (2021), Mauleon and Vannetelbosch (2004), Page, Wooders and Kamat (2005), and Page and Wooders (2009) among others.
} 
one that moves. Asking for maximality can be interpreted as imposing coalitions to play a form of coalitional best responses. We find that social rationalizability may violate coalitional rationality. In other words, the rationality of individuals is not enough to guarantee that coalitional best responses or maximality do emerge endogenously.

The paper is organized as follows. In Section 2 we define social environments and social rationalizability with mediation and we provide an illustration. In Section 3 we show that social rationalizability with mediation satisfies two-player coalitional rationality, while in Section 4 we show that coalitional rationality does not necessarily hold for larger coalitions. In Section 5 we provide an alternative definition of social rationalizability and we show the equivalence with our original definition. Finally, we show that, if we restrict the behavior of the mediator to be consistent with a permutation over alternatives, then we can guarantee that individuals coordinate on the Pareto-dominant outcome.

\section{Rationalizable Social Behaviors with Mediation}

\section{$2.1 \quad$ Social Environments}

As in Chwe (1994), $\Gamma=\left\langle I, Z,\left(u_{i}\right)_{i \in I},\left\{\rightarrow_{S}\right\}_{S \subseteq I, S \neq \emptyset}\right\rangle$ is a social environment, where $I$ is the finite set of individuals, $Z$ is the finite set of outcomes, $\left\{\rightarrow_{S}\right\}_{S \subseteq I, S \neq \emptyset}$ are effectiveness relations defined on $Z$, and, for every individual $i \in I, u_{i}: Z \rightarrow \mathbb{R}$ is her utility function. The relation $\rightarrow_{S}$ represents what coalition $S$ can do: $x_{0} \rightarrow_{S} x_{1}$ means that if $x_{0}$ is the status quo, then coalition $S$ can make $x_{1}$ the new status quo. It does not mean that coalition $S$ can enforce $x_{1}$ no matter what anyone else does; after $S$ moves to $x_{1}$ from $x_{0}$, another coalition $S^{\prime}$ might move to $x_{2}$, where $x_{1} \rightarrow_{S^{\prime}} x_{2}$. A priori no restrictions are imposed on the effectiveness relations $\left\{\rightarrow_{S}\right\}_{S \subseteq I, S \neq \emptyset}$. For example, the effectiveness relation can be empty, $x_{0} \rightarrow_{S} x_{0}$ is allowed for, and $x_{0} \rightarrow_{S} x_{1}$ does not imply $x_{1} \rightarrow_{S} x_{0}$. All actions or moves are public and the individuals care only about the end outcome. Both non-cooperative and cooperative games can be modelled as a social environment.

Figure 1 represents an example of a social environment in which a coalition of two individuals may decide to move from the status quo $x_{0}$, where they both get a utility of 0 , to outcome $x_{1}$ and getting both 1 unit of utility, or to outcome $x_{2}$ and obtaining 2 units of utility each, or to outcome $x_{3}$ and receiving both 3 units of utility. The social

environment is therefore given by $I=\{1,2\}, Z=\left\{x_{0}, x_{1}, x_{2}, x_{3}\right\}$, for $k=1,2,3, x_{0} \rightarrow_{I} x_{k}$ are the only possible moves, and, for $i=1,2$, for $k=0,1,2,3, u_{i}\left(x_{k}\right)=k$.

\subsection{Individual and Social Behaviors}

In what follows, we denote the move $x \rightarrow_{S} y$ of coalition $S$ from $x$ to $y$ by $(x y, S)$. When none of the coalitions is willing or able to move at $x$, then the no-move results, which is denoted by $(x x, \emptyset)$. One has to distinguish between $(x x, \emptyset)$ and $(x x,\{i\})$. Indeed, $(x x,\{i\})$ means that individual $i$ can move from $x$ to $x$. The set of all possible moves is 


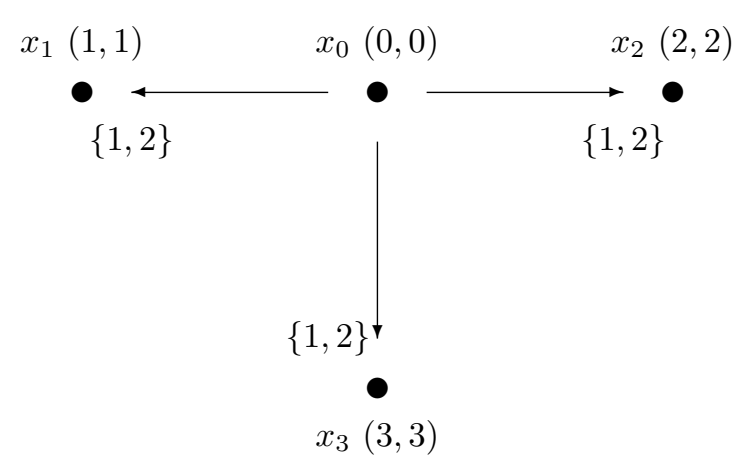

Figure 1: An example of a social environment with two individuals.

given by $M=\left\{(x y, S) \mid x, y \in Z, x \rightarrow_{S} y\right\}$. The set of all possible no-moves is equal to $N=\{(x x, \emptyset) \mid x \in Z\}$. The initial status quo is given by $x_{0} \in Z$. We denote by $h=\left(x_{0}, m_{1}, m_{2}, \ldots, m_{k-1}\right)$ a history of length $k$, where $x_{0} \in Z$ is the initial status quo, for $j=1, \ldots, k-2, m_{j}=\left(m_{j}^{-} m_{j}^{+}, m_{j}^{\mathrm{c}}\right) \in M, m_{k-1} \in M \cup N, m_{1}^{-}=x_{0}$, and $m_{j}^{+}=m_{j+1}^{-}$. The set of all histories is denoted by $H^{*}$.

The length of a history $h \in H^{*}$ is denoted by $\ell(h)$ with $\ell(h)=1$ for $h=\left(x_{0}\right)$. To make the length of a history $h$ explicit, we sometimes use the notation $h^{k}$, where $k$ is the length of the history. Let $h^{-}=x_{0}$ be the initial status quo of $h$ and $h^{+}=m_{\ell(h)-1}^{+}$be the end outcome of $h$. Given $h^{k}$ and $j, k \in \mathbb{N}$ with $j \leq k$, we call $h^{j}$ a sub-history of $h^{k}$ if $h^{j}$ consists of the first $j$ elements of $h^{k}$, and we write $h^{j} \leq h^{k}{ }^{4}$ If we write $h^{j}<h^{k}$, then $h^{j}$ is a proper sub-history of $h^{k}$, so $j<k$.

The set of feasible moves after a history $h \in H^{*}$ such that $m_{\ell(h)-1} \in M$, i.e., a nonterminal history, is given by $M(h)=\left\{m \in M \mid m^{-}=h^{+}\right\}$and, for $i \in I, M_{i}(h)=$ $\{(x y, S) \in M(h) \mid i \in S\}$ denotes the set of feasible moves after history $h$ involving individual $i$. The set containing the no-move after a non-terminal history $h$ is given by $N(h)=\left\{\left(h^{+} h^{+}, \emptyset\right)\right\}$. There are no feasible moves after a history $h$ such that $m_{\ell(h)-1} \in N$, i.e., a terminal history.

We denote by $H$ the set of all non-terminal histories and by $H(J)$ the set of histories with at most $J$ moves. That is, $H(J)=\{h \in H \mid \ell(h) \leq J+1\}$. Temporarily, we fix $J$ and consider only histories in $H(J)$. Let $H_{i}(J)=\left\{h \in H(J) \mid M_{i}(h) \neq \emptyset\right\}$ be the set of histories that contain at most $J$ moves and after which individual $i$ is involved in a move. A social behavior selects after any non-terminal history a move or the no-move. A social behavior is denoted by $b=(b(h))_{h \in H(J)}$, where $b(h) \in M(h) \cup N(h)$. Let $B$ be the set of all social behaviors. Our aim is to find those social behaviors that are rationalizable. From the rationalizable social behaviors, we derive the set of outcomes that are stable. To do this, we examine individual behaviors first.

\footnotetext{
${ }^{4} \mathrm{~A}$ history is different from a path as used in the theory of stable standards of behavior. A path only gives a sequence of outcomes, whereas for a history it also matters which coalition makes the move from one outcome to another.
} 
We model an individual behavior as, for each relevant history, the set of coalitional moves the individual agrees to join and those she decides to block. Observe that the framework of social environments does not exclude that an individual might agree to join more than one coalitional move. Formally, a behavior of individual $i$ is $b_{i}=\left(b_{i}(\cdot \mid\right.$ $h))_{h \in H_{i}(J)}$, where $b_{i}(\cdot \mid h): M_{i}(h) \rightarrow\{0,1\}$. If $b_{i}((x y, S) \mid h)=1$ then $i \in S$ agrees to join in the potential move of coalition $S$ from $x$ to $y$. If $b_{i}((x y, S) \mid h)=0$ then $i \in S$ blocks the move of coalition $S$ from $x$ to $y$. The set of all possible behaviors of individual $i$ is denoted by $B_{i}$.

Let $H_{0}(J)=\{h \in H(J) \mid M(h) \neq \emptyset\}$ be the set of histories that contain at most $J$ moves and after which there is at least one feasible move. It may happen that the individuals agree on more than one move. We denote by $\mathcal{M}(h)=\{\bar{M} \mid \bar{M} \subseteq M(h)\}$ the collection of sets of feasible moves after $h \in H_{0}(J)$. Notice that $\mathcal{M}(h)$ contains at least two elements, one of which is the empty set. For every history $h \in H_{0}(J)$, the so-called agreement function is a mapping $f(\cdot \mid h): \prod_{i \in I} B_{i} \rightarrow \mathcal{M}(h)$ which associates to the profiles of individual behaviors the set of moves after history $h$ on which there is agreement, so $f\left(\left(b_{i}\right)_{i \in I} \mid h\right)=\bar{M}$ if $\forall(x y, S) \in \bar{M}, \forall i \in S$, we have $b_{i}((x y, S) \mid h)=1$ and $\forall(x y, S) \in M(h) \backslash \bar{M}, \exists i \in S$ such that $b_{i}((x y, S) \mid h)=0$. Notice that by this definition we have $f\left(\left(b_{i}\right)_{i \in I} \mid h\right)=\emptyset$ if there is no move on which there is agreement.

A profile of individual behaviors induces, potentially multiple, social behaviors. A social behavior is induced by a profile of individual behaviors if for each history the move prescribed by the social behavior is a move on which there is agreement by all individuals involved in the move, or the no-move when no agreement is possible.

\subsection{Beliefs, Conjectures, and Payoffs}

A problem or a conflict may arise when there are several moves on which agreement is possible. We assume that there is a mediator, referred to as player 0, who always obtains a payoff of zero. The mediator chooses one move among any set of possible agreements after history $h \in H_{0}(J)$. Histories $h \in H(J) \backslash H_{0}(J)$ are automatically followed by the no-move in $N(h)$. Let $b_{0}=\left(b_{0}(\cdot \mid h)\right)_{h \in H_{0}(J)}$ be a behavior of player 0 , where $b_{0}(\cdot \mid h): \mathcal{M}(h) \rightarrow M(h) \cup N(h)$ and $b_{0}(\bar{M} \mid h) \in \bar{M}$ whenever $\bar{M} \neq \emptyset$. If $\bar{M}=\emptyset$, then $b_{0}(\bar{M} \mid h) \in N(h)$. Let $B_{0}$ be the set of behaviors of player 0 .

Rationalizability assumes that individuals form conjectures about each others' behavior, including the behavior of the mediator, player 0 , and then optimize subject to these conjectures. We restrict the individuals to hold uncorrelated conjectures about the behaviors of their opponents and player 0. After each history $h \in H_{i}(J)$ at which individual $i$ is involved in a move, she holds such conjectures. A conjecture of individual $i$ is a mapping $c_{i}: H_{i}(J) \rightarrow \prod_{j \neq i} \Delta\left(B_{j}\right) \times \Delta\left(B_{0}\right){ }^{5}$ We denote by $c_{i}\left(h^{\prime}\right)\left(b_{-i}\right)$ the probability individual $i$ conjectures at history $h^{\prime}$ that her opponents behavior is $b_{-i}$. We denote by

\footnotetext{
${ }^{5}$ As general notation, we denote by $\Delta(X)$ the set of all probability measures on a finite set $X$ and by $\Delta^{0}(X)$ the set of all probability measures giving positive probability to each member of $X$.
} 
$c_{i}^{j}\left(h^{\prime}\right)\left(b_{j}\right) \in \Delta\left(B_{j}\right)$ the probability individual $i$ conjectures at history $h^{\prime}$ that player $j$ 's behavior is $b_{j}$, and by $c_{i}^{0}\left(h^{\prime}\right)\left(b_{0}\right) \in \Delta\left(B_{0}\right)$ the probability individual $i$ conjectures at history $h^{\prime}$ that player 0's behavior is $b_{0}$. There is only a need for an individual to form conjectures when an individual is potentially involved in a move.

A conjecture $c_{i}$ is said to allow for $h \in H_{i}(J)$ if there is an individual behavior $b_{i}$, and there are individual behaviors of her opponents $b_{-i}$ and a behavior $b_{0}$ of player 0 in the support of $c_{i}$, such that $\left(b_{i}, b_{-i}, b_{0}\right)$ allows for $h$. A profile $\left(b_{i}, b_{-i}, b_{0}\right)$ is said to allow for $h=\left(x_{0}, m_{1}, \ldots, m_{k}\right)$ if

(i) $\forall j \in\{1, \ldots, k\}, \forall i \in m_{j}^{\mathrm{c}}, b_{i}\left(m_{j} \mid h^{j}\right)=1$,

(ii) $\forall j \in\{1, \ldots, k\}, b_{0}\left(f\left(\left(b_{i}\right)_{i \in I} \mid h^{j}\right) \mid h^{j}\right)=m_{j}$.

A behavior $b_{i}$ is said to allow for $h$ if there is $\left(b_{-i}, b_{0}\right)$ such that $\left(b_{i}, b_{-i}, b_{0}\right)$ allows for $h$. A set $A_{-i} \subseteq B_{-i}$ is said to allow for $h$ if there is $\left(b_{i}, b_{-i}, b_{0}\right)$ with $b_{-i} \in A_{-i}$ allowing for $h$.

\subsection{Social Rationalizability with Mediation}

We next propose a definition of social rationalizability with mediation that is motivated by extensive-form rationalizability as defined in Pearce (1984) and is based on a reduction procedure. Social rationalizability is derived from two assumptions: (1) individuals are rational, and (2) this is common knowledge at the initial status quo. A rational individual $i$ maximizes her expected payoff at each history $h$ reached by the play, subject to her consistent updating system of conjectures, $c_{i}$.

Definition 1. A consistent updating system for individual $i$ is a mapping $c_{i}: H_{i}(J) \rightarrow$ $\prod_{j \neq i} \Delta\left(B_{j}\right) \times \Delta\left(B_{0}\right)$ such that, for all $g, h \in H_{i}(J)$,

(i) $c_{i}(h)$ allows for $h$,

(ii) if $g<h$ and $c_{i}(g)$ allows for $h$, then $c_{i}(g)=c_{i}(h)$.

The consistency of the updating system requires that the conjecture at history $h$ is such that $h$ is allowed for and that no conjecture is changed unless falsified. Individuals update according to Bayes rule whenever possible. Formally, social rationalizability with mediation is the result of a reduction procedure that is defined as follows.

Definition 2. Let $P^{0}=\prod_{i \in I} B_{i}$. For $n \geq 1, P^{n}=\prod_{i \in I} P_{i}^{n}$ is inductively defined as follows: for all $i \in I, b_{i} \in P_{i}^{n}$ if

(i) $b_{i} \in P_{i}^{n-1}$,

(ii) there exists a consistent updating system $c_{i}$ such that for all $h^{\prime} \in H_{i}(J)$ that are allowed by $b_{i}$ and $P_{-i}^{n-1}$ it holds that 
(iia) $c_{i}\left(h^{\prime}\right) \in \prod_{j \neq i} \Delta^{0}\left(P_{j}^{n-1}\right) \times \Delta^{0}\left(B_{0}\right)$,

(iib) for all $\widehat{b}_{i} \in P_{i}^{n-1}, U_{i}\left(h^{\prime}\right)\left(b_{i}, c_{i}\right) \geq U_{i}\left(h^{\prime}\right)\left(b_{i} / \widehat{b}_{i}^{h^{\prime}}, c_{i}\right)$, where $U_{i}\left(h^{\prime}\right)\left(b_{i}, c_{i}\right)$ denotes the expected payoff of individual $i$ given $\left(b_{i}, c_{i}\right)$ conditional on reaching history $h^{\prime}$ and $b_{i} / \widehat{b}_{i}^{h^{\prime}}$ is the behavior which results from $b_{i}$ when behavior at $h^{\prime}$ and its followers $g>h^{\prime}$ is specified by $\widehat{b}_{i}$.

The set $P^{\infty}(J)=\lim _{n \rightarrow \infty} P^{n}$ is the set of rationalizable individual behaviors where histories contain at most $J$ moves.

In Definition 2 individuals are cautious, meaning that they assign positive probability to all behaviors of their opponents in $P_{-i}^{n-1}$ and of player 0 in $B_{0}$.

Let $S^{\infty}(J)$ denote the set of rationalizable social behaviors. A social behavior $b$ belongs to $S^{\infty}(J)$ if there exists $\left(b_{i}\right)_{i \in I} \in P^{\infty}(J)$ such that, for every $h \in H(J), b(h) \in M(h)$ implies $b(h) \in f\left(\left(b_{i}\right)_{i \in I} \mid h\right)$ and $b(h) \in N(h)$ implies $f\left(\left(b_{i}\right)_{i \in I} \mid h\right)=\emptyset$.

Let $h^{-1}(\{x\})=\left\{h \in H(J+1) \mid \ell(h)=J+2\right.$ and $\left.h^{+}=x\right\} \cup\left\{h \in H^{*} \backslash H \mid \ell(h) \leq J+2\right.$ and $\left.h^{+}=x\right\}$ be the set of histories of length at most $J+2$ ending at $x \in Z$. We denote by $Z_{J}^{\infty}\left(x_{0}\right)$ the set of rationalizable outcomes with initial status quo $x_{0} \in Z$. It is given by $Z_{J}^{\infty}\left(x_{0}\right)=\left\{x \in Z \mid \exists\left(x_{0}, m_{1}, \ldots, m_{k}\right) \in h^{-1}(\{x\}), \exists b \in S^{\infty}(J)\right.$ such that $\left.\forall j=1, \ldots, k, b\left(x_{0}, m_{1}, \ldots, m_{j-1}\right)=m_{j}\right\}$. The set of socially rationalizable outcomes, $Z^{\infty}\left(x_{0}\right)$, is obtained by letting $J$ go to infinity, $Z^{\infty}\left(x_{0}\right)=\lim \sup _{J \rightarrow \infty} Z_{J}^{\infty}\left(x_{0}\right)$. The set of socially rationalizable outcomes is never empty.

Theorem 1. $Z^{\infty}\left(x_{0}\right) \neq \emptyset$.

The proof of this theorem is similar to the proof of Theorem 2 in Herings, Mauleon and Vannetelbosch (2004) and is therefore omitted.

\subsection{An Illustration}

Remember that individuals hold conjectures about how a mediator (or a player whose payoff is always zero) is going to choose a move among any set of feasible moves after any history. That is, each individual who has the possibility of moving after a certain history holds beliefs about the move chosen by the mediator (i.e. player 0 ) for each possible set of moves on which the individuals could agree to join. Then, given the conjecture of individual $i$ about each others' behavior and her belief on the moves chosen by player 0 among any set of feasible moves, individual $i$ chooses the behavior that maximizes her expected utility.

For the social environment of Figure 1, social rationalizability with mediation works as follows. To simplify notation, we denote by $(1,0,1)$ for instance the behavior of player $i$ when $b_{i}\left(\left(x_{1},\{1,2\}\right) \mid\left(x_{0}\right)\right)=1, b_{i}\left(\left(x_{2},\{1,2\}\right) \mid\left(x_{0}\right)\right)=0$, and $b_{i}\left(\left(x_{3},\{1,2\}\right) \mid\left(x_{0}\right)\right)=1$. In the first iteration, we can see that the behaviors $(0,0,0),(1,0,0)$, and $(0,1,0)$ are never best responses whatever the conjecture of individual $i$ about the behavior of individual 


\begin{tabular}{ccccc}
\hline \hline \multicolumn{5}{c}{$b_{i}$} \\
$b_{j}$ & $(0,0,1)$ & $(1,0,1)$ & $(0,1,1)$ & $(1,1,1)$ \\
$(0,0,0)$ & 0 & 0 & 0 & 0 \\
$(0,0,1)$ & $\frac{3}{4}$ & $\frac{3}{7}$ & $\frac{3}{7}$ & $\frac{3}{10}$ \\
$(1,0,0)$ & 0 & $\frac{3}{7}$ & 0 & $\frac{3}{10}$ \\
$(0,1,0)$ & 0 & 0 & $\frac{3}{7}$ & $\frac{3}{10}$ \\
$(1,1,0)$ & 0 & 0 & 0 & 0 \\
$(0,1,1)$ & 0 & 0 & 0 & 0 \\
$(1,0,1)$ & 0 & 0 & 0 & 0 \\
$(1,1,1)$ & $\frac{1}{4}$ & $\frac{1}{7}$ & $\frac{1}{7}$ & $\frac{1}{10}$ \\
\hline \hline
\end{tabular}

Table 1: Unique best response and conjecture.

$j$ and whatever the belief on the choice of player 0 . In fact, the behavior $(1,0,0)$ gives always a higher expected utility for player $i$ than $(0,0,0)$, the behavior $(1,1,0)$ gives always a higher expected utility for player $i$ than $(1,0,0)$, and the behavior $(0,1,1)$ gives always a higher expected utility for player $i$ than $(0,1,0)$. However, the behavior $(1,1,0)$ cannot be eliminated since it is the unique best response against the conjecture that player $j$ will have the behavior $(1,0,0)$ with probability $3 / 7$, the behavior $(0,1,0)$ with probability $3 / 7$, and the behavior $(1,1,1)$ with probability $1 / 7$, and assuming that the mediator chooses the move to the best outcome when the set of moves on which there is agreement is formed by the first two moves (i.e., the move to $x_{1}$ and to $x_{2}$ ), while she chooses the move to the worst outcome for any other set of possible agreements. In Table 1 we give conjectures against which each behavior $b_{i}$, different from the four behaviors already discussed, is the unique best response, assuming that the mediator only chooses the move to the best outcome when the set of possible agreements coincides with the moves that $b_{i}$ does not block. The uniqueness of the best response guarantees that there are also cautious conjectures against which the behavior is the unique best response.

Hence, after the first iteration, we can only eliminate the behaviors $(0,0,0),(1,0,0)$, and $(0,1,0)$. In the second iteration, we can show that the behavior $(1,1,0)$ is never a best response whatever the conjecture of individual $i$ about the behaviors of individual $j$ not eliminated in the first iteration, and whatever the belief on the choice of the mediator. Notice that the behavior $(0,1,1)$ gives always a weakly greater expected utility for player $i$ than the behavior $(1,1,0)$ given that $(1,0,0)$ has been eliminated in the first iteration. For the other behaviors, it can be shown that there are conjectures about the behavior of individual $j$ and beliefs on the choice of the mediator such that each of them is the unique best response against that conjecture and belief. In Table 2 we give conjectures on the behavior of player $j$ against which each of these behaviors $b_{i}$ is the unique best response, assuming that the mediator only chooses the move to the best outcome when the set of possible agreements coincides with the moves that $b_{i}$ does not block when $b_{i} \neq(1,1,1)$. For $b_{i}=(1,1,1)$, the mediator only chooses the move to the best outcome when there 


\begin{tabular}{ccccc}
\hline \hline & \multicolumn{4}{c}{$b_{i}$} \\
$b_{j}$ & $(0,0,1)$ & $(1,0,1)$ & $(0,1,1)$ & $(1,1,1)$ \\
$(0,0,1)$ & $\frac{3}{4}$ & 0 & 0 & 0 \\
$(1,1,0)$ & 0 & $\frac{1}{7}$ & $\frac{3}{7}$ & $\frac{1}{2}$ \\
$(0,1,1)$ & 0 & 0 & $\frac{3}{7}$ & 0 \\
$(1,0,1)$ & 0 & $\frac{3}{7}$ & 0 & 0 \\
$(1,1,1)$ & $\frac{1}{4}$ & $\frac{3}{7}$ & $\frac{1}{7}$ & $\frac{1}{2}$ \\
\hline \hline
\end{tabular}

Table 2: Unique best response and conjecture.

is agreement on the moves to $x_{1}$ and $x_{2}$ or there is agreement on any move. As before, the uniqueness of the best response guarantees that there are also cautious conjectures against which the behavior is the unique best response.

Next, in the third iteration, once individual $i$ knows that player $j$ will play a behavior that never blocks the move to $x_{3}$, her behavior $(0,0,1)$ will be the unique best response against any cautious conjecture about the behavior of player $j$ and the mediator. Hence, $(0,0,1)$ is the unique socially rationalizable behavior and the Pareto-dominant outcome, $x_{3}$, is the unique socially rationalizable outcome.

The next two sections study the case of two players who can move to an arbitrary number of Pareto-ranked outcomes and the general case of more than two players who can move to an arbitrary number of Pareto-ranked outcomes.

\section{Two-Player Coalitional Rationality}

We investigate if social rationalizability with mediation satisfies, in general, the property of coalitional rationality. That is, in a situation in which a coalition of two or more individuals can move from a status quo $x_{0}$ to different outcomes that are Pareto ranked, does social rationalizability with mediation prescribe that players coordinate on the outcome that Pareto dominates all others? In the example of Figure 1 with two players and three possible moves, we have seen that the Pareto-dominant outcome is the unique socially rationalizable outcome. Does this hold for the general case of two players and arbitrary Pareto-ranked payoffs?

For the case with two possible moves, using similar arguments as in the case with three possible moves, the behaviors $(0,0)$ and $(1,0)$ are eliminated in the first iteration and the behavior $(1,1)$ in the second iteration, leaving the Pareto-dominant outcome again as the unique socially rationalizable outcome. This section therefore focuses on the case with at least four possible moves.

Consider the social environment $\Gamma^{2}$, where $I=\{1,2\}, Z=\left\{x_{0}, x_{1}, \ldots, x_{K}\right\}$ with $K \geq 4$, the outcomes are Pareto ranked,

$$
u_{i}\left(x_{K}\right)>u_{i}\left(x_{K-1}\right)>\cdots>u_{i}\left(x_{1}\right)>u_{i}\left(x_{0}\right)=0, \quad i \in I,
$$


and the feasible moves are given by $x_{0} \rightarrow_{I} x_{k}$, where $k=1, \ldots, K$. We say that social rationalizability with mediation satisfies coalitional rationality if it selects the Paretodominant outcome $x_{K}$ as the unique solution.

In the social environment $\Gamma^{2}$, we have, for every $i \in I, H_{i}=\left\{\left(x_{0}\right)\right\}$ and $M\left(x_{0}\right)=$ $M_{i}\left(x_{0}\right)=\left\{\left(x_{0} x_{1}, I\right),\left(x_{0} x_{2}, I\right), \ldots,\left(x_{0} x_{K}, I\right)\right\}$. Since there is only one non-terminal history, in this section we drop histories from the notation for behaviors, conjectures, and utilities. A behavior of individual $i \in I$ is denoted by $b_{i}=\left(b_{i 1}, \ldots, b_{i K}\right)$, where, for $k \in\{1, \ldots, K\}$, $b_{i k}=b_{i}\left(x_{0} x_{k}, I\right)$. A behavior of player 0 is of the form $b_{0}=\left(b_{0}(\bar{M})\right)_{\emptyset \neq \bar{M} \subseteq M}$ with $b_{0}(\bar{M}) \in$ $\bar{M}$.

We introduce some additional notation. In this section, from now on, we fix an individual $i \in I$ and take $j$ to be the other individual in $I$. Given $b_{i} \in B_{i}$, let $A_{i}\left(b_{i}\right)=$ $\left\{m_{i} \in M_{i} \mid b_{i}\left(m_{i}\right)=1\right\}$ be the set of moves on which individual $i$ agrees and let $a_{i}\left(b_{i}\right)=$ $\# A_{i}\left(b_{i}\right)$ be the cardinality of this set. For $b_{i} \in B_{i}$ with $a_{i}\left(b_{i}\right) \geq 1$, we define $\bar{k}=\max \{k \in$ $\left.\{1, \ldots, K\} \mid b_{i k}=1\right\}$ and $\underline{k}=\min \left\{k \in\{1, \ldots, K\} \mid b_{i k}=1\right\}$ as the number of the best and the worst outcome, respectively, on which individual $i$ agrees. For $k \in\{1, \ldots, K\}$, we denote by $e(k)$ the individual behavior such that the $k$ th component is 1 and the other components are 0 , and by $\mathbf{1}$ the vector of all ones, that is, the behavior where the individual agrees to join every move.

We now show that coalitional rationality holds in general in the two-player social environment $\Gamma^{2}$. In order to do so, we use Lemmas 1-8. Lemma 1, whose proof is obvious and left to the reader, states that if a behavior of individual $i$ is the unique best response against a conjecture $c_{i} \in \Delta\left(\widetilde{B}_{j}\right) \times \Delta\left(B_{0}\right)$, where $\widetilde{B}_{j}$ is some non-empty subset of $B_{j}$, then it is also the unique best response against some cautious conjecture $c_{i}^{*} \in \Delta^{0}\left(\widetilde{B}_{j}\right) \times \Delta^{0}\left(B_{0}\right)$.

Lemma 1. Take any $b_{i} \in B_{i}$. Let $\widetilde{B}_{j}$ be a non-empty subset of $B_{j}$. If there exists $c_{i} \in$ $\Delta\left(\widetilde{B}_{j}\right) \times \Delta\left(B_{0}\right)$ such that, for every $b_{i}^{\prime} \in B_{i} \backslash\left\{b_{i}\right\}, U_{i}\left(b_{i}, c_{i}\right)>U_{i}\left(b_{i}^{\prime}, c_{i}\right)$, then there exists $c_{i}^{*} \in \Delta^{0}\left(\widetilde{B}_{j}\right) \times \Delta^{0}\left(B_{0}\right)$ such that, for every $b_{i}^{\prime} \in B_{i} \backslash\left\{b_{i}\right\}, U_{i}\left(b_{i}, c_{i}^{*}\right)>U_{i}\left(b_{i}^{\prime}, c_{i}^{*}\right)$.

Lemma 2 claims that the individual behavior $b_{i}=(0, \ldots, 0)$, so individual $i$ blocks all moves, is never a best response whatever the cautious conjecture $c_{i} \in \Delta^{0}\left(B_{j}\right) \times \Delta^{0}\left(B_{0}\right)$. Indeed, the behavior $b_{i}^{\prime}=e(K)$, so $b_{i}^{\prime}$ is the same as $b_{i}$ except that individual $i$ joins the move to $x_{K}$, is always a strictly better response. All proofs that are not in the main text can be found in the appendix.

Lemma 2. Let $b_{i}=(0, \ldots, 0)$. For $b_{i}^{\prime}=e(K)$, for every $c_{i} \in \Delta^{0}\left(B_{j}\right) \times \Delta^{0}\left(B_{0}\right)$, it holds that $U_{i}\left(b_{i}^{\prime}, c_{i}\right)>U_{i}\left(b_{i}, c_{i}\right)$.

Lemma 3 states that any individual behavior $b_{i}=e(k)$ with $k<K$, so individual $i$ only agrees to join a single move different from the move to $x_{K}$, is never a best response whatever the cautious conjecture $c_{i} \in \Delta^{0}\left(B_{j}\right) \times \Delta^{0}\left(B_{0}\right)$. Indeed, the behavior $b_{i}^{\prime}$, where $b_{i}^{\prime}$ is the same as $b_{i}$ except that individual $i$ joins the move to $x_{k+1}$ is always a strictly better response. 
Lemma 3. Let $b_{i}=e(k)$ for some $k<K$. For $b_{i}^{\prime}=e(k)+e(k+1)$, for every $c_{i} \in$ $\Delta^{0}\left(B_{j}\right) \times \Delta^{0}\left(B_{0}\right)$, it holds that $U_{i}\left(b_{i}^{\prime}, c_{i}\right)>U_{i}\left(b_{i}, c_{i}\right)$.

Lemma 4 establishes that for any behavior $b_{i}$ where individual $i$ agrees to move to at least two outcomes or to move only to $x_{K}$ there exists a conjecture $c_{i} \in \Delta\left(B_{j}\right) \times \Delta\left(B_{0}\right)$ such that $b_{i}$ is her unique best response. This conjecture is such that it puts positive weight on $b_{j}=e(k)$ for every $k$ such that $b_{i k}=1$ as well as on $b_{j}=\mathbf{1}$ and puts zero weight on any other behavior. The positive weights on $b_{j}=e(k)$ guarantee that $b_{i}$ gives higher utility than a behavior $b_{i}^{\prime}$ which blocks moves that are not blocked by $b_{i}$. The positive weight on $b_{j}=\mathbf{1}$, together with a suitably chosen conjecture on the behavior of the mediator, implies that $b_{i}$ outperforms any $b_{i}^{\prime}$ that agrees to strictly more moves than $b_{i}$.

Lemma 4. Take any $b_{i} \in B_{i}$ such that either $a_{i}\left(b_{i}\right) \geq 2$ or $b_{i}=e(K)$. Then, for all $b_{i}^{\prime} \in B_{i} \backslash\left\{b_{i}\right\}$, we have $U_{i}\left(b_{i}, c_{i}\right)>U_{i}\left(b_{i}^{\prime}, c_{i}\right)$, where $c_{i} \in \Delta\left(B_{j}\right) \times \Delta\left(B_{0}\right)$ is such that

$c_{i}^{j}\left(b_{j}\right)= \begin{cases}\frac{u_{i}\left(x_{K}\right)}{\left[a_{i}\left(b_{i}\right) \cdot u_{i}\left(x_{K}\right)+u_{i}\left(x_{1}\right)\right]} & \text { if there is } k \in\{1, \ldots, K\} \text { such that } b_{j}=e(k) \text { and } b_{i k}=1 \\ \frac{u_{i}\left(x_{1}\right)}{\left[a_{i}\left(b_{i}\right) \cdot u_{i}\left(x_{K}\right)+u_{i}\left(x_{1}\right)\right]} & \text { if } b_{j}=1 \\ 0 & \text { otherwise }\end{cases}$

and $c_{i}^{0}\left(b_{0}\right)=1$ where $b_{0}$ selects the move to the best outcome in $\bar{M}$ if $\bar{M}=A_{i}\left(b_{i}\right)$ and the move to the worst outcome in $\bar{M}$ in any other non-empty set $\bar{M} \subseteq M$.

From Lemmas 2, 3, and 4 we have that $P_{i}^{1}=\left\{b_{i} \in B_{i} \mid a_{i}\left(b_{i}\right) \geq 2\right\} \cup\{e(K)\}$.

For the second iteration, we first show that the behavior $b_{i}=e(1)+e(2) \in P_{i}^{1}$ does not belong to $P_{i}^{2}$. In fact, the behavior $b_{i}^{\prime}=(0,1, \ldots, 1) \in P_{i}^{1}$ gives higher utility than $b_{i}$ against all relevant cautious conjectures.

Lemma 5. Consider the behavior $b_{i}=e(1)+e(2) \in P_{i}^{1}$. Take the behavior $b_{i}^{\prime}=$ $(0,1, \ldots, 1) \in P_{i}^{1}$. Then, for every $c_{i} \in \Delta^{0}\left(P_{j}^{1}\right) \times \Delta^{0}\left(B_{0}\right)$, we have $U_{i}\left(b_{i}^{\prime}, c_{i}\right)>U_{i}\left(b_{i}, c_{i}\right)$.

We continue by showing that any behavior $b_{i} \in P_{i}^{1}$ different from $e(1)+e(2)$ belongs to $P_{i}^{2}$, i.e., is the best response of player $i$ in $P_{i}^{1}$ against some cautious conjecture in $\Delta^{0}\left(P_{j}^{1}\right) \times \Delta^{0}\left(B_{0}\right)$. We achieve this by showing that $b_{i}$ is the unique best response against a particular conjecture $c_{i} \in \Delta\left(P_{j}^{1}\right) \times \Delta\left(B_{0}\right)$.

Lemma 6. Let $b_{i} \in P_{i}^{1} \backslash\{e(1)+e(2)\}$. Then, for all $b_{i}^{\prime} \in P_{i}^{1} \backslash\left\{b_{i}\right\}$, we have $U_{i}\left(b_{i}, c_{i}\right)>$ $U_{i}\left(b_{i}^{\prime}, c_{i}\right)$, where, for $\varepsilon>0$ sufficiently small, $c_{i} \in \Delta\left(P_{j}^{1}\right) \times \Delta\left(B_{0}\right)$ is such that

$$
c_{i}^{j}\left(b_{j}\right)= \begin{cases}1-\varepsilon-\varepsilon^{2} & \text { if } b_{j}=b_{i} \\ \varepsilon & \text { if } b_{j}=1 \\ \varepsilon^{2} & \text { if } b_{j}=e(1)+e(\max \{2, \underline{k}\})\end{cases}
$$

and $c_{i}^{0}\left(b_{0}\right)=1$ where $b_{0}$ selects the move to the best outcome in $\bar{M}$ if $\bar{M}=A_{i}\left(b_{i}\right)$ and the move to the worst outcome in $\bar{M}$ for any other non-empty set $\bar{M} \subseteq M$. 
From Lemmas 5 and 6 it follows that $P_{i}^{2}=P_{i}^{1} \backslash\{e(1)+e(2)\}$. The set $P_{i}^{2}$ consists of the behaviors $b_{i}$ such that $a_{i}\left(b_{i}\right) \geq 2$ and $\bar{k} \geq 3$ as well as the behavior $b_{i}=e(K)$.

Lemma 7 shows that the behaviors $b_{i} \in P_{i}^{2}$ that block the moves to the best $K-3$ outcomes do not belong to $P_{i}^{3}$. The behavior $b_{i}^{\prime}=(0,0,1, \ldots, 1) \in P_{i}^{2}$ gives a greater utility against any cautious conjecture in $\Delta^{0}\left(P_{j}^{2}\right) \times \Delta^{0}\left(B_{0}\right)$.

Lemma 7. Consider a behavior $b_{i} \in P_{i}^{2}$ such that $\bar{k}=3$. Take the behavior $b_{i}^{\prime}=$ $(0,0,1, \ldots, 1) \in P_{i}^{2}$. Then, for every $c_{i} \in \Delta^{0}\left(P_{j}^{2}\right) \times \Delta^{0}\left(B_{0}\right)$, we have $U_{i}\left(b_{i}^{\prime}, c_{i}\right)>U_{i}\left(b_{i}, c_{i}\right)$.

We continue by showing that any behavior $b_{i} \in P_{i}^{2}$ such that $\bar{k} \geq 4$ belongs to $P_{i}^{3}$, i.e., is the best response of player $i$ in $P_{i}^{2}$ against some cautious conjecture in $\Delta^{0}\left(P_{j}^{2}\right) \times$ $\Delta^{0}\left(B_{0}\right)$. We achieve this by showing that $b_{i}$ is the unique best response against a particular conjecture $c_{i} \in \Delta\left(P_{j}^{2}\right) \times \Delta\left(B_{0}\right)$.

Lemma 8. Let $b_{i} \in P_{i}^{2}$ be such that $\bar{k} \geq 4$. Then, for all $b_{i}^{\prime} \in P_{i}^{2} \backslash\left\{b_{i}\right\}$, we have $U_{i}\left(b_{i}, c_{i}\right)>U_{i}\left(b_{i}^{\prime}, c_{i}\right)$, where, for $\varepsilon>0$ sufficiently small, $c_{i} \in \Delta\left(P_{j}^{2}\right) \times \Delta\left(B_{0}\right)$ is such that

$$
c_{i}^{j}\left(b_{j}\right)= \begin{cases}1-\varepsilon-\varepsilon^{2} & \text { if } b_{j}=b_{i} \\ \varepsilon & \text { if } b_{j}=\mathbf{1} \\ \varepsilon^{2} & \text { if } b_{j}=e(1)+e(2)+e(\max \{3, \underline{k}\})\end{cases}
$$

and $c_{i}^{0}\left(b_{0}\right)=1$ where $b_{0}$ selects the move to the best outcome in $\bar{M}$ if $\bar{M}=A_{i}\left(b_{i}\right)$ and the move to the worst outcome in $\bar{M}$ for any other non-empty set $\bar{M} \subseteq M$.

Hence, by Lemmas 7 and 8 we have that every behavior $b_{i}$ in $P_{i}^{3}$ is such that $a_{i}\left(b_{i}\right) \geq 2$ and $\bar{k} \geq 4$ or $b_{i}=e(K)$. Proceeding in this way, we obtain the following proposition.

Proposition 1. For $1 \leq k \leq K-1$, it holds that $P_{i}^{k}=\left\{b_{i} \in B_{i} \mid a_{i}\left(b_{i}\right) \geq 2\right.$ and $\bar{k} \geq$ $k+1\} \cup\{e(K)\}$.

Proof. The proposition has already been shown for $k=1,2,3$. Assume the proposition is true for some $k \leq K-2$. We show the proposition to hold for $k+1$.

We eliminate any behavior $b_{i} \in P_{i}^{k}$ such that $\bar{k}=k+1$ by the behavior $b_{i}^{\prime}=$ $\sum_{\ell=\bar{k}+1}^{K} e(\ell)$. The proof follows the steps of the proof of Lemma 7 .

The other behaviors $b_{i}$ in $P_{i}^{k}$ are such that $a_{i}\left(b_{i}\right) \geq 2$ and $\bar{k}>k+1$ or $b_{i}=e(K)$. Such a behavior $b_{i}$ is the unique best response, for $\varepsilon>0$ sufficiently small, against the conjecture $c_{i} \in \Delta\left(P_{j}^{k}\right) \times \Delta\left(B_{0}\right)$ defined by

$$
c_{i}^{j}\left(b_{j}\right)= \begin{cases}1-\varepsilon-\varepsilon^{2} & \text { if } b_{j}=b_{i} \\ \varepsilon & \text { if } b_{j}=\mathbf{1} \\ \varepsilon^{2} & \text { if } b_{j}=\sum_{\ell=1}^{k} e(\ell)+e(\max \{k+1, \underline{k}\})\end{cases}
$$

and $c_{i}^{0}\left(b_{0}\right)=1$ where $b_{0}$ selects the move to the best outcome in $\bar{M}$ if $\bar{M}=A_{i}\left(b_{i}\right)$ and the move to the worst outcome in $\bar{M}$ for any other non-empty set $\bar{M} \subseteq M$. The proof follows the steps of the proof of Lemma 8. 
Putting these results together, we are able to show the following main result.

Theorem 2. Consider the social environment $\Gamma^{2}$. There is a unique behavior of individual $i$ that is socially rationalizable, $P_{i}^{K}=P_{i}^{\infty}=\{e(K)\}$.

Proof. From Proposition 1, we have $P_{i}^{K-1}=\left\{b_{i} \in B_{i} \mid \bar{k}=K\right\}$. Finally, for every $c_{i} \in \Delta^{0}\left(P_{j}^{K-1}\right) \times \Delta^{0}\left(B_{0}\right)$, the behavior $b_{i}=e(K)$ gives to individual $i$ a utility equal to $U_{i}\left(b_{i}, c_{i}\right)=u_{i}\left(x_{K}\right)$. For every $b_{i}^{\prime} \in P_{i}^{K-1} \backslash\left\{b_{i}\right\}$, for every $c_{i} \in \Delta^{0}\left(P_{j}^{K-1}\right) \times \Delta^{0}\left(B_{0}\right)$, $U_{i}\left(b_{i}^{\prime}, c_{i}\right)<u_{i}\left(x_{K}\right)$ because for some $k<K, b_{i k}^{\prime}=1$, and the cautiousness of $c_{i}$ implies that with positive probability the opponent of $i$ follows a behavior $b_{j}$ such that $b_{j k}=1$ and the mediator chooses $b_{0}\left(f\left(b_{i}, b_{j}\right)\right)=x_{k}$, which leads to utility $u_{i}\left(x_{k}\right)<u_{i}\left(x_{K}\right)$. So, $P_{i}^{K}=\{e(K)\}=P_{i}^{\infty}$.

The above result implies that social rationalizability with mediation satisfies the property of two-player coalitional rationality. When the outcomes can be Pareto ranked, a coalition of two players always selects the Pareto-dominant outcome. Each individual only agrees to move to the Pareto dominating outcome and blocks all other moves.

Corollary 1. Consider the social environment $\Gamma^{2}$. We have $Z^{\infty}\left(x_{0}\right)=\left\{x_{K}\right\}$.

\section{Coalitional Rationality for More Than Two Players}

Does social rationalizability with mediation satisfy, in general, the property of coalitional rationality? We now provide an example of a social environment with three players which violates this property.

Example 1. Consider the social environment $\Gamma^{3}$ in which the coalition of three individuals may decide to move from the status quo $x_{0}$, where they all get a utility equal to 0 , to outcome $x_{1}$ obtaining each 1 unit of utility, or to outcome $x_{2}$ all getting 2 units of utility, or to outcome $x_{3}$ and receive 3 units of utility each. That is, $I=\{1,2,3\}$, $Z=\left\{x_{0}, x_{1}, x_{2}, x_{3}\right\}$, for every $k \in\{1,2,3\}, x_{0} \rightarrow_{I} x_{k}$ are the only possible moves, and, for every $i \in I$, for every $k \in\{0,1,2,3\}, u_{i}\left(x_{k}\right)=k$.

In this social environment $\Gamma^{3}$, we have $I\left(x_{0}\right)=I, H_{i}=\left\{\left(x_{0}\right)\right\}$ and, for every $i \in I$, $M_{i}\left(x_{0}\right)=M\left(x_{0}\right)=\left\{\left(x_{0} x_{1}, I\right),\left(x_{0} x_{2}, I\right),\left(x_{0} x_{3}, I\right)\right\}$. As in Section 3, since there is only one non-terminal history, in this section we drop histories from the notation for behaviors, conjectures, and utilities. A behavior of individual $i \in I$ is denoted by $b_{i}=\left(b_{i 1}, b_{i 2}, b_{i 3}\right)$, where, for $k \in\{1,2,3\}, b_{i k}=b_{i}\left(x_{0} x_{k}, I\right)$. The set of possible behaviors of individual $i$ is

$$
B_{i}=\{(0,0,0),(1,0,0),(0,1,0),(0,0,1),(1,1,0),(1,0,1),(0,1,1),(1,1,1)\} .
$$

A behavior of player 0 is of the form $b_{0}=\left(b_{0}(\bar{M})\right)_{\emptyset \neq \bar{M} \subseteq M}$ with $b_{0}(\bar{M}) \in \bar{M}$. In this section, from now on, we fix an individual $i \in I$.

By Definition $2, P_{i}^{0}=B_{i}$. We show that the behaviors $(0,0,0),(1,0,0)$, and $(0,1,0)$ do not belong to $P_{i}^{1}$. Let $b_{i}$ be any such behavior. Take $b_{i}^{\prime} \in B_{i}$ such that $b_{i}^{\prime}=b_{i}+(0,0,1)$. 
It is quite straightforward that for all $c_{i} \in \prod_{j \in I \backslash\{i\}} \Delta^{0}\left(B_{j}\right) \times \Delta^{0}\left(B_{0}\right), U_{i}\left(b_{i}, c_{i}\right)<U_{i}\left(b_{i}^{\prime}, c_{i}\right)$. Indeed, the behaviors $b_{i}$ and $b_{i}^{\prime}$ give the same payoff to individual $i$ against the opponents' behaviors $b_{-i}$ whenever the set of moves on which the opponents of individual $i$ agree does not include the move to outcome $x_{3}$, i.e., when some opponents behavior $b_{j}$ is such that $b_{j 3}=0$. But, $b_{i}^{\prime}$ does strictly better than $b_{i}$ against the opponents' behaviors $b_{-i}$ such that $b_{j 3}=1$ for all $j \in I \backslash\{i\}$ and a mediator that chooses the move to $x_{3}$ whenever that move belongs to $\bar{M}$.

Next, we show that for every $b_{i} \in B_{i} \backslash\{(0,0,0),(1,0,0),(0,1,0)\}$ there exists $c_{i} \in$ $\prod_{j \in I \backslash\{i\}} \Delta\left(B_{j}\right) \times \Delta\left(B_{0}\right)$ such that $b_{i}$ is the unique best response against $c_{i}$. We can extend Lemma 1 to the setting of Example 1 and conclude that $b_{i} \in P_{i}^{1}$.

In fact, we can use conjectures that are similar to the ones used in Lemma 4 . We define the conjecture $c_{i} \in \prod_{j \in I \backslash\{i\}} \Delta\left(P_{j}^{1}\right) \times \Delta\left(B_{0}\right)$ by

$c_{i}^{j}\left(b_{j}\right)= \begin{cases}\frac{u_{i}\left(x_{K}\right)}{\left[a_{i}\left(b_{i}\right) \cdot u_{i}\left(x_{K}\right)+u_{i}\left(x_{1}\right)\right]} & \text { if there is } k \in\{1, \ldots, K\} \text { such that } b_{j}=e(k) \text { and } b_{i k}=1 \\ \overline{\left.a_{i}\left(b_{i}\right) \cdot u_{i}\left(x_{K}\right)+u_{i}\left(x_{1}\right)\right]} & \text { if } b_{j}=\mathbf{1} \\ 0 & \text { otherwise }\end{cases}$

and $c_{i}^{0}\left(b_{0}\right)=1$ where $b_{0}$ selects the move to the best outcome in $\bar{M}$ if $\bar{M}=A_{i}\left(b_{i}\right)$ and the move to the worst outcome in $\bar{M}$ in any other non-empty set $\bar{M} \subseteq M$.

The possible sets of moves on which both opponents agree are respectively equal to $\emptyset$, for any $k \in\{1, \ldots, K\}$ such that $b_{i k}=1,\left\{\left(x_{0} x_{k}, I\right)\right\}$, and $M$. The definition of $b_{0}$ implies that under $b_{i}$ the move to the best feasible outcome results, irrespective of the realization of $\bar{M}$. Any other behavior $b_{i}^{\prime}$ that is a best response should therefore also result in the move to the best feasible outcome. Since opponents may only agree on the move to $\left\{\left(x_{0} x_{k}, I\right)\right\}$ for any $k \in\{1, \ldots, K\}$ such that $b_{i k}=1$, this implies that $A_{i}\left(b_{i}\right) \subseteq A_{i}\left(b_{i}^{\prime}\right)$. Since the opponents may also agree on the set of all moves and $b_{i}^{\prime} \neq b_{i}, b_{0}$ selects the move to the worst outcome in $A_{i}\left(b_{i}^{\prime}\right)$ in this case. Since $b_{i} \in B_{i} \backslash\{(0,0,0),(1,0,0),(0,1,0)\}$ and $A_{i}\left(b_{i}\right) \subseteq A_{i}\left(b_{i}^{\prime}\right)$, the move to the worst outcome in $A_{i}\left(b_{i}^{\prime}\right)$ is inferior to the move to the best outcome in $A_{i}\left(b_{i}\right)$. This shows that $b_{i}$ is the unique best response to $c_{i}$. Hence, $P_{i}^{1}=\{(0,0,1),(1,1,0),(1,0,1),(0,1,1),(1,1,1)\}$.

In the second iteration, individual $i$ knows that any other individual $j$ will play a behavior in $P_{j}^{1}$. We continue by defining for each behavior $b_{i} \in P_{i}^{1}$ a conjecture $c_{i} \in$ $\prod_{j \in I \backslash\{i\}} \Delta\left(P_{j}^{1}\right) \times \Delta\left(B_{0}\right)$ such that $b_{i}$ is the unique best response against $c_{i}$.

(i) The behavior $b_{i}=(0,0,1)$ is the unique best response against the conjecture $c_{i}$ such that, for $j \in I \backslash\{i\}$,

$$
c_{i}^{j}\left(b_{j}\right)= \begin{cases}3 / 4 & \text { if } b_{j}=(0,0,1) \\ 1 / 4 & \text { if } b_{j}=\mathbf{1}\end{cases}
$$

and $c_{i}^{0}\left(b_{0}\right)=1$ where $b_{0}$ is such that the move to the worst outcome in $\bar{M}$ is selected for any non-empty set $\bar{M} \subseteq M$. Indeed, for every $b_{i}^{\prime} \in P_{1}^{i} \backslash\left\{b_{i}\right\}$, we have that $U_{i}\left(b_{i}, c_{i}\right)=3>U_{i}\left(b_{i}^{\prime}, c_{i}\right)$. 
(ii) Let $I \backslash\{i\}=\left\{j, j^{\prime}\right\}$. The behavior $b_{i}=(1,1,0)$ is the unique best response against the conjecture $c_{i}$ such that

$$
\begin{aligned}
c_{i}^{j}\left(b_{j}\right) & = \begin{cases}7 / 8 & \text { if } b_{j}=(1,1,0) \\
1 / 8 & \text { if } b_{j}=\mathbf{1}\end{cases} \\
c_{i}^{j^{\prime}}\left(b_{j^{\prime}}\right) & = \begin{cases}7 / 8 & \text { if } b_{j^{\prime}}=(1,0,1) \\
1 / 8 & \text { if } b_{j^{\prime}}=\mathbf{1}\end{cases}
\end{aligned}
$$

and $c_{i}^{0}\left(b_{0}\right)=1$ where $b_{0}$ selects the move to the best outcome in $\bar{M}$ if $\bar{M}=A_{i}\left(b_{i}\right)$ and the move to the worst outcome in $\bar{M}$ in any other non-empty set $\bar{M} \subseteq M$. Indeed, for every $b_{i}^{\prime} \in P_{1}^{i} \backslash\left\{b_{i}\right\}$, we have that $U_{i}\left(b_{i}, c_{i}\right)=72 / 64>U_{i}\left(b_{i}^{\prime}, c_{i}\right)$.

(iii) Let $I \backslash\{i\}=\left\{j, j^{\prime}\right\}$. The behavior $b_{i}=(1,0,1)$ is the unique best response against the conjecture $c_{i}$ such that

$$
\begin{aligned}
c_{i}^{j}\left(b_{j}\right) & = \begin{cases}7 / 8 & \text { if } b_{j}=(1,0,1) \\
1 / 8 & \text { if } b_{j}=\mathbf{1}\end{cases} \\
c_{i}^{j^{\prime}}\left(b_{j^{\prime}}\right) & = \begin{cases}7 / 8 & \text { if } b_{j^{\prime}}=(1,1,0) \\
1 / 8 & \text { if } b_{j^{\prime}}=\mathbf{1}\end{cases}
\end{aligned}
$$

and $c_{i}^{0}\left(b_{0}\right)=1$ where $b_{0}$ selects the move to the best outcome in $\bar{M}$ if $\bar{M}=A_{i}\left(b_{i}\right)$ and the move to the worst outcome in $\bar{M}$ in any other non-empty set $\bar{M} \subseteq M$. Indeed, for every $b_{i}^{\prime} \in P_{1}^{i} \backslash\left\{b_{i}\right\}$, we have that $U_{i}\left(b_{i}, c_{i}\right)=80 / 64>U_{i}\left(b_{i}^{\prime}, c_{i}\right)$.

(iv) Let $I \backslash\{i\}=\left\{j, j^{\prime}\right\}$. The behavior $b_{i}=(0,1,1)$ is the unique best response against the conjecture $c_{i}$ such that

$$
\begin{aligned}
c_{i}^{j}\left(b_{j}\right) & = \begin{cases}7 / 8 & \text { if } b_{j}=(0,1,1) \\
1 / 8 & \text { if } b_{j}=\mathbf{1}\end{cases} \\
c_{i}^{j^{\prime}}\left(b_{j^{\prime}}\right) & = \begin{cases}7 / 8 & \text { if } b_{j^{\prime}}=(1,1,0) \\
1 / 8 & \text { if } b_{j^{\prime}}=\mathbf{1}\end{cases}
\end{aligned}
$$

and $c_{i}^{0}\left(b_{0}\right)=1$ where $b_{0}$ selects the move to the best outcome in $\bar{M}$ if $\bar{M}=A_{i}\left(b_{i}\right)$ and the move to the worst outcome in $\bar{M}$ in any other non-empty set $\bar{M} \subseteq M$. Indeed, for every $b_{i}^{\prime} \in P_{1}^{i} \backslash\left\{b_{i}\right\}$, we have that $U_{i}\left(b_{i}, c_{i}\right)=136 / 64>U_{i}\left(b_{i}^{\prime}, c_{i}\right)$.

(v) The behavior $b_{i}=(1,1,1)$ is the unique best response against the conjecture $c_{i}$ such that, for $j \in I \backslash\{i\}$,

$$
c_{i}^{j}\left(b_{j}\right)=\left\{\begin{array}{cc}
6 / 13 & \text { if } b_{j}=(1,1,0) \\
3 / 13 & \text { if } b_{j}=(1,0,1) \\
3 / 13 & \text { if } b_{j}=(0,1,1) \\
1 / 13 & \text { if } b_{j}=1
\end{array}\right.
$$


and $c_{i}^{0}\left(b_{0}\right)=1$ where $b_{0}$ selects the move to the best outcome in $\bar{M}$ in any non-empty set $\bar{M} \subseteq M$. Indeed, for every $b_{i}^{\prime} \in P_{1}^{i} \backslash\left\{b_{i}\right\}$, we have that $U_{i}\left(b_{i}, c_{i}\right)=351 / 169>$ $U_{i}\left(b_{i}^{\prime}, c_{i}\right)$.

We find that $P_{i}^{1}=P_{i}^{2}=P_{i}^{\infty}$. The set of socially rationalizable outcomes with mediation coincides with the set of initial outcomes, $Z^{\infty}\left(x_{0}\right)=\left\{x_{0}, x_{1}, x_{2}, x_{3}\right\}$. Therefore, social rationalizability with mediation does not satisfy the property of coalitional rationality when the number of players is greater than two.

\section{Discussion}

\subsection{An Equivalent Definition of Social Rationalizability}

An alternative definition of social rationalizability with mediation is obtained by adapting Battigalli's (1997) notion of extensive-form rationalizability to social environments. Social rationalizability based on the approach of Battigalli is derived from two assumptions: (1) individuals are rational and endowed with a hierarchy of hypotheses, and (2) this is common knowledge at the initial status quo. In Definition $3, R_{i}^{1}$ is the set of individual behaviors of $i \in I$ that are individually rational. Higher degrees of rationality are constructed recursively.

Definition 3. Let $R^{0}=\prod_{i \in I} B_{i}$. For $n \geq 1, R^{n}=\prod_{i \in I} R_{i}^{n}$ is inductively defined as follows: for all $i \in I, b_{i} \in R_{i}^{n}$ if there exists a consistent updating system $c_{i}$ such that

(i) for all $h^{\prime} \in H_{i}(J), c_{i}\left(h^{\prime}\right) \in \prod_{j \neq i} \Delta^{0}\left(R_{j}^{k^{*}}\right) \times \Delta^{0}\left(B_{0}\right)$ where $k^{*}$ is the maximal element in $\{0,1, \ldots, n-1\}$ such that $R_{-i}^{k^{*}}$ allows for $h^{\prime}$,

(ii) for all $h^{\prime} \in H_{i}(J)$, if $b_{i}$ allows for $h^{\prime}$, then $b_{i}$ is a best response to $c_{i}\left(h^{\prime}\right)$ at $h^{\prime}$, that is, for all $\widehat{b}_{i} \in B_{i}, U_{i}\left(h^{\prime}\right)\left(b_{i}, c_{i}\right) \geq U_{i}\left(h^{\prime}\right)\left(b_{i} / \widehat{b}_{i}^{h^{\prime}}, c_{i}\right)$, where $b_{i} / \widehat{b}_{i}^{h^{\prime}}$ is the behavior which results from $b_{i}$ when behavior at $h^{\prime}$ and its followers $g>h^{\prime}$ is specified by $\widehat{b}_{i}$.

The set $R^{\infty}(J)=\lim _{n \rightarrow \infty} R^{n}$ is the set of rationalizable individual behaviors where histories contain at most $J$ moves.

The sequence $\left(R_{j}^{1}\right)_{j \neq i},\left(R_{j}^{2}\right)_{j \neq i},\left(R_{j}^{3}\right)_{j \neq i}, \ldots$ in Definition 3 represents for individual $i$ a hierarchy of increasingly strong hypotheses about the behavior of individuals $j \neq$ $i$. When individual $i$ adopts a behavior $b_{i} \in R_{i}^{\infty}(J)$, she always holds the strongest hypothesis which is consistent with the history reached (part (i) in Definition 3) and optimizes accordingly.

Theorem 3. For all $n \geq 0, R^{n}=P^{n}$.

Theorem 3 claims that both definitions of social rationalizability are equivalent. The proof of this theorem is similar to the proof of Theorem 1 in Battigalli (1997) and is therefore omitted. From Theorem 3, we have that $R^{\infty}(J)=P^{\infty}(J)$. Notice that the computation of the set of socially rationalizable outcomes is greatly simplified by using the reduction procedure of Definition 2. 


\subsection{A Permutational Mediator}

Assume the mediator, player 0 , is known to behave as follows. A behavior $b_{0}=\left(b_{0}(\cdot\right.$ $h))_{h \in H(J)}$ of player 0 is such that after each history $h$ she chooses a permutation of $M(h)$ that indicates the order according to which moves are implemented. For $\bar{M} \in \mathcal{M}(h)$, the highest ordered element in $\bar{M}$ according to this permutation is implemented. We refer to such a mediator as a permutational mediator.

Consider the social environment $\Gamma^{K}$ where $I$ contains a finite number of individuals, $Z=\left\{x_{0}, x_{1}, \ldots, x_{K}\right\}$, and there is one outcome which strictly Pareto dominates all other outcomes,

$$
u_{i}\left(x_{K}\right)>u_{i}\left(x_{k}\right)>u_{i}\left(x_{0}\right), \quad i \in I, k \in\{2, \ldots, K-1\} .
$$

The possible moves are given by $x_{0} \rightarrow_{I} x_{k}$ for $k=1, \ldots, K$. We say that social rationalizability with mediation satisfies coalitional rationality if it selects the Pareto-dominant outcome $x_{K}$.

Theorem 4. Consider the social environment $\Gamma^{K}$ with a permutational mediator. There is a unique behavior of individual $i \in I$ that is socially rationalizable, $P_{i}^{\infty}=\{e(K)\}$.

The proof of this theorem is similar to the proof of Theorem 3 in Herings, Mauleon and Vannetelbosch (2000) and Theorem 6 in Herings, Mauleon and Vannetelbosch (2004) and is therefore omitted.

Corollary 2. Consider the social environment $\Gamma^{K}$ with a permutational mediator. There is a unique socially rationalizable outcome, $Z^{\infty}=\left\{x_{K}\right\}$.

It can be shown that, in the case of two players, social rationalizability with mediation requires $K-2$ additional rounds of elimination to obtain coordination on the Paretodominant outcome compared to social rationalizability with a permutational mediator.

In the case of the social environment $\Gamma^{3}$ (Example 1 ), social rationalizability with a permuational mediator satisfies the property of coalitional rationality while social rationalizability with mediation does not. The reason behind this fact is that once $P_{i}^{1}=\{(0,0,1)$, $(1,1,0),(1,0,1),(0,1,1),(1,1,1)\}$, the behavior $(1,1,0)$ that blocks the move to the Pareto-dominant outcome cannot be eliminated when the mediator can arbitrarily select different moves for different sets of possible agreements. On the contrary, a permutational mediator holds a ranking over the feasible moves and chooses, for any set of possible agreements, the agreement that is ranked highest.

Finally, instead of having a permutational mediator, one could simply assume that all individuals have uniform implementability prior-beliefs on the set $M(h)$. The likelihood of a particular move in the set of moves on which there is agreement is then determined by Bayesian updating. This results in uniform ex-post beliefs on the agreement set. Assuming that the implementability prior-beliefs of the individuals are cautious, Herings, Mauleon and Vannetelbosch (2000) show that social rationalizability ends up selecting the Pareto-dominant outcome. 


\subsection{Conclusion}

Social environments constitute a framework in which it is possible to study how groups of agents interact in a society. We have proposed a new solution concept for social environments that is based on individual rationality, called social rationalizability with mediation. One of the basic steps in our construction is to model individual behavior in a social environment, which makes a social environment apt to an analysis based on individual rationality. Individual behavior within a coalition is modelled as the decision to agree to a coalitional move or to block it. Since a coalition may have several moves available, and more than one coalition may have the option to move at the same time, there can be many moves on which there is agreement. Individuals therefore have conjectures about how a mediator, a player whose payoff is always zero, is going to solve the conflicts of interest.

Social rationalizability with mediation identifies which coalitions are likely to form and which outcomes might occur when the individuals are rational and this is common knowledge at the initial status quo. We have shown that for all social environments the set of socially rationalizable outcomes with mediation is non-empty. Social rationalizability with mediation aims to be a weak concept that rules out with confidence. Its nonemptiness makes it applicable to cases where traditional solution concepts fail to make predictions. It is also not too weak in the sense that it satisfies individual rationality. As a theory of social behavior, we have analyzed if social rationalizability with mediation is consistent with elementary notions of coalitional rationality. For instance, when a coalition has to choose between a number of Pareto-ranked moves, it should select the Pareto dominating one for sure. We have shown that social rationalizability with mediation does not satisfy the property of coalitional rationality for coalitions of more than two players. In fact, restrictions on the behavior of the mediator are needed to guarantee that individuals coordinate on the Pareto-dominant outcome. So, coalitional rationality does not necessarily follow from individual behaviors of rational individuals.

\section{Acknowledgements}

Ana Mauleon and Vincent Vannetelbosch are, respectively, Research Director and Senior Research Associate of the National Fund for Scientific Research (FNRS). Financial support from the Fonds de la Recherche Scientifique - FNRS research grant T.0143.18 is gratefully acknowledged. 


\section{Appendix}

\section{Proof of Lemma 2.}

(i) For all $b_{j} \in B_{j}$ with $b_{j K}=0$, we have that

$$
U_{i}\left(b_{i}^{\prime}, b_{j}, c_{i}^{0}\right)=U_{i}\left(b_{i}, b_{j}, c_{i}^{0}\right)=0 .
$$

(ii) For all $b_{j} \in B_{j}$ with $b_{j K}=1$, we have that

$$
u_{i}\left(x_{K}\right)=U_{i}\left(b_{i}^{\prime}, b_{j}, c_{i}^{0}\right)>U_{i}\left(b_{i}, b_{j}, c_{i}^{0}\right)=0 .
$$

It follows that, for every $c_{i} \in \Delta^{0}\left(B_{j}\right) \times \Delta^{0}\left(B_{0}\right), U_{i}\left(b_{i}^{\prime}, c_{i}\right)>U_{i}\left(b_{i}, c_{i}\right)$.

\section{Proof of Lemma 3.}

(i) For all $b_{j} \in B_{j}$ with $b_{j k}=b_{j k+1}=0$, we have

$$
U_{i}\left(b_{i}, b_{j}, c_{i}^{0}\right)=U_{i}\left(b_{i}^{\prime}, b_{j}, c_{i}^{0}\right)=u_{i}\left(x_{0}\right)
$$

(ii) For all $b_{j} \in B_{j}$ with $b_{j k}=1$ and $b_{j k+1}=0$, we have

$$
U_{i}\left(b_{i}, b_{j}, c_{i}^{0}\right)=U_{i}\left(b_{i}^{\prime}, b_{j}, c_{i}^{0}\right)=u_{i}\left(x_{k}\right)
$$

(iii) For all $b_{j} \in B_{j}$ with $b_{j k}=0$ and $b_{j k+1}=1$, we have

$$
U_{i}\left(b_{i}, b_{j}, c_{i}^{0}\right)=0<U_{i}\left(b_{i}^{\prime}, b_{j}, c_{i}^{0}\right)=u_{i}\left(x_{k+1}\right)
$$

(iv) For all $b_{j} \in B_{j}$ with $b_{j k}=b_{j k+1}=1$, we have

$$
u_{i}\left(x_{k}\right)=U_{i}\left(b_{i}, b_{j}, c_{i}^{0}\right)<U_{i}\left(b_{i}^{\prime}, b_{j}, c_{i}^{0}\right) .
$$

Hence, for every $c_{i} \in \Delta^{0}\left(B_{j}\right) \times \Delta^{0}\left(B_{0}\right)$, it holds that $U_{i}\left(b_{i}^{\prime}, c_{i}\right)>U_{i}\left(b_{i}, c_{i}\right)$.

\section{Proof of Lemma 4 .}

(i) Consider the behavior $b_{i}=e(K)$. Then,

$$
U_{i}\left(b_{i}, c_{i}\right)=\left[\frac{u_{i}\left(x_{K}\right)}{u_{i}\left(x_{K}\right)+u_{i}\left(x_{1}\right)}\right] \cdot u_{i}\left(x_{K}\right)+\left[\frac{u_{i}\left(x_{1}\right)}{u_{i}\left(x_{K}\right)+u_{i}\left(x_{1}\right)}\right] \cdot u_{i}\left(x_{K}\right)=u_{i}\left(x_{K}\right) .
$$

For any $b_{i}^{\prime} \in B_{i} \backslash\{e(K)\}$ it holds that

$$
U_{i}\left(b_{i}^{\prime}, c_{i}\right) \leq\left[\frac{u_{i}\left(x_{K}\right)}{u_{i}\left(x_{K}\right)+u_{i}\left(x_{1}\right)}\right] \cdot u_{i}\left(x_{K}\right)+\left[\frac{u_{i}\left(x_{1}\right)}{u_{i}\left(x_{K}\right)+u_{i}\left(x_{1}\right)}\right] \cdot u_{i}\left(x_{K-1}\right)<u_{i}\left(x_{K}\right),
$$

where the expression after the weak inequality uses the fact that $f\left(b_{i}^{\prime}, \mathbf{1}\right)$ contains a move leading to an outcome different from $x_{K}$, so $b_{0}$ selects a move leading to an outcome worse than $x_{K}$, or $f\left(b_{i}^{\prime}, \mathbf{1}\right)$ is equal to the empty set and outcome $x_{0}$ results.

(ii) Consider any behavior $b_{i} \in B_{i}$ such that $a_{i}\left(b_{i}\right) \geq 2$. We have that

$$
U_{i}\left(b_{i}, c_{i}\right)=\left[\frac{u_{i}\left(x_{K}\right)}{a_{i}\left(b_{i}\right) \cdot u_{i}\left(x_{K}\right)+u_{i}\left(x_{1}\right)}\right] \cdot \sum_{\left\{k \in\{1, \ldots, K\} \mid b_{i k}=1\right\}} u_{i}\left(x_{k}\right)+\left[\frac{u_{i}\left(x_{1}\right)}{a_{i}\left(b_{i}\right) \cdot u_{i}\left(x_{K}\right)+u_{i}\left(x_{1}\right)}\right] \cdot u_{i}\left(x_{\bar{k}}\right) .
$$


Two cases have to be considered. In Case 1 we consider $b_{i}^{\prime} \in B_{i}$ such that, for some $k \in\{1, \ldots, K\}, b_{i k}=1$ and $b_{i k}^{\prime}=0$. In Case 2 we take $b_{i}^{\prime} \in B_{i} \backslash\left\{b_{i}\right\}$ such that $b_{i k}=1$ implies $b_{i k}^{\prime}=1$.

Case 1. It follows that

$$
\begin{aligned}
U_{i}\left(b_{i}^{\prime}, c_{i}\right) \leq & {\left[\frac{u_{i}\left(x_{K}\right)}{a_{i}\left(b_{i}\right) \cdot u_{i}\left(x_{K}\right)+u_{i}\left(x_{1}\right)}\right] \cdot\left[\sum_{\left\{k \in\{1, \ldots, K\} \mid b_{i k}=1\right\}} u_{i}\left(x_{k}\right)-u_{i}\left(x_{\underline{k}}\right)\right] } \\
& +\left[\frac{u_{i}\left(x_{1}\right)}{a_{i}\left(b_{i}\right) \cdot u_{i}\left(x_{K}\right)+u_{i}\left(x_{1}\right)}\right] \cdot u_{i}\left(x_{K}\right) \\
\leq & {\left[\frac{u_{i}\left(x_{K}\right)}{a_{i}\left(b_{i}\right) \cdot u_{i}\left(x_{K}\right)+u_{i}\left(x_{1}\right)}\right] \cdot\left[\sum_{\left\{k \in\{1, \ldots, K\} \mid b_{i k}=1\right\}} u_{i}\left(x_{k}\right)\right] } \\
< & U_{i}\left(b_{i}, c_{i}\right) .
\end{aligned}
$$

Case 2. It holds that

$$
\begin{aligned}
U_{i}\left(b_{i}^{\prime}, c_{i}\right) \leq & {\left[\frac{u_{i}\left(x_{K}\right)}{a_{i}\left(b_{i}\right) \cdot u_{i}\left(x_{K}\right)+u_{i}\left(x_{1}\right)}\right] \cdot\left[\sum_{\left\{k \in\{1, \ldots, K\} \mid b_{i k}=1\right\}} u_{i}\left(x_{k}\right)\right] } \\
& +\left[\frac{u_{i}\left(x_{1}\right)}{a_{i}\left(b_{i}\right) \cdot u_{i}\left(x_{K}\right)+u_{i}\left(x_{1}\right)}\right] \cdot u_{i}\left(x_{\underline{k}}\right) \\
< & U_{i}\left(b_{i}, c_{i}\right),
\end{aligned}
$$

where the expression after the weak inequality uses the fact that $f\left(b_{i}^{\prime}, \mathbf{1}\right)$ is not equal to $f\left(b_{i}, \mathbf{1}\right)$ and contains the move to outcome $x_{\underline{k}}$ as an element, so $b_{0}$ selects a move leading to an outcome which is at best equal to $x_{\underline{k}}$.

\section{Proof of Lemma 5.}

Since the behaviors $(0, \ldots, 0)$ and $e(1)$ of individual $j$ do not belong to $P_{j}^{1}$, it follows that, for every conjecture $c_{i} \in \Delta^{0}\left(P_{j}^{1}\right) \times \Delta^{0}\left(B_{0}\right)$,

$$
U_{i}\left(b_{i}^{\prime}, c_{i}\right) \geq u_{i}\left(x_{2}\right) \geq U_{i}\left(b_{i}, c_{i}\right)
$$

Since such a conjecture $c_{i}$ puts positive weight on the behavior $b_{j}=e(K)$ and

$$
U_{i}\left(b_{i}^{\prime}, e(K), c_{i}^{0}\right)=u_{i}\left(x_{K}\right)>u_{i}\left(x_{0}\right)=U_{i}\left(b_{i}, e(K), c_{i}^{0}\right)
$$

we conclude that $U_{i}\left(b_{i}^{\prime}, c_{i}\right)>U_{i}\left(b_{i}, c_{i}\right)$.

\section{Proof of Lemma 6.}

It holds that

$$
U_{i}\left(b_{i}, c_{i}\right)=\left(1-\varepsilon-\varepsilon^{2}\right) \cdot u_{i}\left(x_{\bar{k}}\right)+\varepsilon \cdot u_{i}\left(x_{\bar{k}}\right)+\varepsilon^{2} \cdot u_{i}\left(x_{\underline{k}}\right),
$$

where for $\underline{k}=1$ the expression in the last term follows from the fact that

$$
\left(x_{0} x_{1}, I\right) \in f\left(b_{i}, e(1)+e(2)\right)=f\left(b_{i}, e(1)+e(\max \{2, \underline{k}\})\right) \neq A_{i}\left(b_{i}\right),
$$

so $b_{i}$ selects the worst move in $f\left(b_{i}, e(1)+e(2)\right)$, which is equal to $\left(x_{0} x_{1}, I\right)$.

Let $b_{i}^{\prime} \in P_{i}^{1} \backslash\left\{b_{i}\right\}$.

If $b_{i \bar{k}}^{\prime}=0$, then, for $\varepsilon>0$ sufficiently small,

$$
U_{i}\left(b_{i}^{\prime}, c_{i}\right) \leq\left(1-\varepsilon-\varepsilon^{2}\right) \cdot u_{i}\left(x_{\bar{k}-1}\right)+\left(\varepsilon+\varepsilon^{2}\right) \cdot u_{i}\left(x_{K}\right)<U_{i}\left(b_{i}, c_{i}\right),
$$


where the strict inequality makes use of the fact that $\varepsilon$ is sufficiently small.

Assume $b_{i \bar{k}}^{\prime}=1$. If there is $k<\bar{k}$ such that $b_{i k}^{\prime}=1$, then, for $\varepsilon>0$ sufficiently small,

$$
U_{i}\left(b_{i}^{\prime}, c_{i}\right) \leq\left(1-\varepsilon-\varepsilon^{2}\right) \cdot u_{i}\left(x_{\bar{k}}\right)+\varepsilon \cdot u_{i}\left(x_{\bar{k}-1}\right)+\varepsilon^{2} \cdot u_{i}\left(x_{K}\right)<U_{i}\left(b_{i}, c_{i}\right),
$$

where the strict inequality makes use of the fact that $\varepsilon$ is sufficiently small.

Assume the smallest $k$ for which $b_{i k}^{\prime}=1$ is equal to $\bar{k}$. It follows that $b_{i} \neq e(K)$, since $\bar{k}=K$ together with the assumption that the smallest $k$ for which $b_{i k}^{\prime}=1$ is equal to $\bar{k}$ implies $b_{i}^{\prime}=e(K)$. Since $b_{i}^{\prime} \neq b_{i}$ we have that $b_{i} \neq e(K)$. Since $b_{i} \in P_{i}^{1}$ and $b_{i} \neq e(1)+e(2)$, it also follows that $\bar{k} \geq 3$. We have that

$$
U_{i}\left(b_{i}^{\prime}, c_{i}\right)=\left(1-\varepsilon-\varepsilon^{2}\right) \cdot u_{i}\left(x_{\bar{k}}\right)+\varepsilon \cdot u_{i}\left(x_{\bar{k}}\right)<U_{i}\left(b_{i}, c_{i}\right),
$$

where the second term in the expression after the equality follows from the fact that $f\left(b_{i}^{\prime}, \mathbf{1}\right)=A_{i}\left(b_{i}^{\prime}\right) \neq A_{i}\left(b_{i}\right)$, so the worst move $\left(x_{0} x_{\bar{k}}, I\right)$ in $A_{i}\left(b_{i}^{\prime}\right)$ is selected by $b_{0}$. The expression after the equality also uses that $b_{i} \neq e(K)$, so $\underline{k}<\bar{k}$, and $f\left(b_{i}^{\prime}, e(1)+\right.$ $e(\max \{2, \underline{k}\}))=\emptyset$.

\section{Proof of Lemma 7.}

Since, for every behavior $b_{j} \in P_{j}^{2}$, there is $k \geq 3$ such that $b_{j k}=1$, it follows that, for every conjecture $c_{i} \in \Delta^{0}\left(P_{j}^{2}\right) \times \Delta^{0}\left(B_{0}\right)$,

$$
U_{i}\left(b_{i}^{\prime}, c_{i}\right) \geq u_{i}\left(x_{3}\right) \geq U_{i}\left(b_{i}, c_{i}\right) .
$$

Since such a conjecture $c_{i}$ puts positive weight on the behavior $b_{j}=e(K)$ and

$$
U_{i}\left(b_{i}^{\prime}, e(K), c_{i}^{0}\right)=u_{i}\left(x_{K}\right)>u_{i}\left(x_{0}\right)=U_{i}\left(b_{i}, e(K), c_{i}^{0}\right),
$$

we conclude that $U_{i}\left(b_{i}^{\prime}, c_{i}\right)>U_{i}\left(b_{i}, c_{i}\right)$.

\section{Proof of Lemma 8.}

We have that

$$
U_{i}\left(b_{i}, c_{i}\right)=\left(1-\varepsilon-\varepsilon^{2}\right) \cdot u_{i}\left(x_{\bar{k}}\right)+\varepsilon \cdot u_{i}\left(x_{\bar{k}}\right)+\varepsilon^{2} \cdot u_{i}\left(x_{\underline{k}}\right),
$$

where if $\underline{k} \leq 2$ the expression in the last term follows from the fact that

$$
\left(x_{0} x_{\underline{k}}, I\right) \in f\left(b_{i}, e(1)+e(2)+e(3)\right)=f\left(b_{i}, e(1)+e(2)+e(\max \{3, \underline{k}\})\right) \neq A_{i}\left(b_{i}\right),
$$

so we find that $b_{i}$ selects the worst move in $f\left(b_{i}, e(1)+e(2)+e(3)\right)$, which is equal to $\left(x_{0} x_{\underline{k}}, I\right)$. The inequality in the last expression makes use of the fact that $\bar{k} \geq 4$.

Let $b_{i}^{\prime} \in P_{i}^{2} \backslash\left\{b_{i}\right\}$. If $b_{i \bar{k}}^{\prime}=0$, then, for $\varepsilon>0$ sufficiently small,

$$
U_{i}\left(b_{i}^{\prime}, c_{i}\right) \leq\left(1-\varepsilon-\varepsilon^{2}\right) \cdot u_{i}\left(x_{\bar{k}-1}\right)+\left(\varepsilon+\varepsilon^{2}\right) \cdot u_{i}\left(x_{K}\right)<U_{i}\left(b_{i}, c_{i}\right),
$$

where the strict inequality makes use of the fact that $\varepsilon$ is sufficiently small. 
Assume $b_{i \bar{k}}^{\prime}=1$. If there is $k<\bar{k}$ such that $b_{i k}^{\prime}=1$, then, for $\varepsilon>0$ sufficiently small,

$$
U_{i}\left(b_{i}^{\prime}, c_{i}\right) \leq\left(1-\varepsilon-\varepsilon^{2}\right) \cdot u_{i}\left(x_{\bar{k}}\right)+\varepsilon \cdot u_{i}\left(x_{\bar{k}-1}\right)+\varepsilon^{2} \cdot u_{i}\left(x_{K}\right)<U_{i}\left(b_{i}, c_{i}\right),
$$

where the strict inequality makes use of the fact that $\varepsilon$ is sufficiently small.

Assume the smallest $k$ for which $b_{i k}^{\prime}=1$ is equal to $\bar{k}$. It follows that $b_{i} \neq e(K)$, since $\bar{k}=K$ together with the assumption that the smallest $k$ for which $b_{i k}^{\prime}=1$ is equal to $\bar{k}$ implies $b_{i}^{\prime}=e(K)$. Since $b_{i}^{\prime} \neq b_{i}$ it follows that $b_{i} \neq e(K)$. We have that

$$
U_{i}\left(b_{i}^{\prime}, c_{i}\right)=\left(1-\varepsilon-\varepsilon^{2}\right) \cdot u_{i}\left(x_{\bar{k}}\right)+\varepsilon \cdot u_{i}\left(x_{\bar{k}}\right)<U_{i}\left(b_{i}, c_{i}\right),
$$

where the second term in the expression after the equality follows from the fact that $f\left(b_{i}^{\prime}, \mathbf{1}\right)=A_{i}\left(b_{i}^{\prime}\right) \neq A_{i}\left(b_{i}\right)$, so the worst move $\left(x_{0} x_{\bar{k}}, I\right)$ in $A_{i}\left(b_{i}^{\prime}\right)$ is selected by $b_{0}$. The expression after the equality also uses that $b_{i} \neq e(K)$, so $\underline{k}<\bar{k}$, and $f\left(b_{i}^{\prime}, e(1)+e(2)+\right.$ $e(\max \{3, \underline{k}\}))=\emptyset$.

\section{References}

[1] Battigalli, P., 1997. On rationalizability in extensive games. Journal of Economic Theory 74, 40-61.

[2] Bernheim, D., 1984. Rationalizable strategic behavior. Econometrica 52, 1007-1028.

[3] Bloch, F. and A. van den Nouweland, 2020. Farsighted stability with heterogeneous expectations. Games and Economic Behavior 121, 32-54.

[4] Chwe, M.S., 1994. Farsighted coalitional stability. Journal of Economic Theory 63, 299-325

[5] Diamantoudi, E. and L. Xue, 2003. Farsighted stability in hedonic games. Social Choice and Welfare 21, 39-61.

[6] Dutta, B., S. Ghosal and D. Ray, 2005. Farsighted network formation. Journal of Economic Theory 122, 143-164.

[7] Dutta, B. and H. Vartiainen, 2020. Coalition formation and history dependence. Theoretical Economics 15, 159-197.

[8] Dutta, B. and R. Vohra, 2017. Rational expectations and farsighted stability. Theoretical Economics 12, 1191-1227.

[9] Herings, P.J.J., A. Mauleon and V. Vannetelbosch, 2000. Social rationalizability. CentER Discussion Paper 2000-81, Tilburg University, The Netherlands.

[10] Herings, P.J.J., A. Mauleon and V. Vannetelbosch, 2004. Rationalizability for social environments. Games and Economic Behavior 49, 135-156. 
[11] Herings, P.J.J., A. Mauleon and V. Vannetelbosch, 2009. Farsightedly stable networks. Games and Economic Behavior 67, 526-541.

[12] Herings, P.J.J., A. Mauleon and V. Vannetelbosch, 2010. Coalition formation among farsighted agents. Games 1, 286-298.

[13] Herings, P.J.J., A. Mauleon and V. Vannetelbosch, 2019. Stability of networks under horizon-K farsightedness. Economic Theory 68, 177-200.

[14] Herings, P.J.J., A. Mauleon and V. Vannetelbosch, 2020. Matching with myopic and farsighted players. Journal of Economic Theory 190, 105125.

[15] Karos, D. and L. Robles, 2021. Full farsighted rationality. Games and Economic Behavior 130, 409-424.

[16] Kimya, M., 2020. Equilibrium coalitional behavior. Theoretical Economics 15, 669714.

[17] Luo, C., A. Mauleon and V. Vannetelbosch, 2021. Network formation with myopic and farsighted players. Economic Theory 71, 1283-1317.

[18] Mauleon, A. and V. Vannetelbosch, 2004. Farsightedness and cautiousness in coalition formation games with positive spillovers. Theory and Decision 56, 291-324.

[19] Mauleon, A., V. Vannetelbosch and W. Vergote, 2011. von Neumann Morgenstern farsightedly stable sets in two-sided matching. Theoretical Economics 6, 499-521.

[20] Page, F.H., Jr. and M. Wooders, 2009. Strategic basins of attraction, the path dominance core, and network formation games. Games and Economic Behavior 66, 462487.

[21] Page, F.H., Jr., M. Wooders and S. Kamat, 2005. Networks and farsighted stability. Journal of Economic Theory 120, 257-269.

[22] Pearce, D.G., 1984. Rationalizable strategic behavior and the problem of perfection. Econometrica 52, 1029-1050.

[23] Ray, D. and R. Vohra, 2015. The farsighted stable set. Econometrica 83, 977-1011.

[24] Ray, D. and R. Vohra, 2019. Maximality in the farsighted stable set. Econometrica 87, 1763-1779.

[25] Shimoji, M. and J. Watson, 1998. Conditional dominance, rationalizability, and game forms. Journal of Economic Theory 83, 161-195.

[26] Vannetelbosch, V., 1999. Rationalizability and equilibrium in N-person sequential bargaining. Economic Theory 14, 353-371. 
[27] Xue, L., 1998. Coalitional stability under perfect foresight. Economic Theory 11, 603-627. 